Inspiration, imagination and implementation: International Year of Light activities of the Photonics Academy of Wales at Bangor (PAWB)

Ray Davies, K. Alan Shore

Ray Davies, K. Alan Shore, "Inspiration, imagination and implementation: International Year of Light activities of the Photonics Academy of Wales at Bangor (PAWB)," Proc. SPIE 9946, Optics Education and Outreach IV, 994605 (27 September 2016); doi: 10.1117/12.2235270

SPIE Event: SPIE Optical Engineering + Applications, 2016, San Diego, California, United States 


\title{
Inspiration, Imagination and Implementation: International Year of Light Activities of the Photonics Academy of Wales@ Bangor (PAWB)
}

\author{
Ray Davies and K Alan Shore \\ Photonics Academy of Wales @ Bangor (PAWB) \\ Bangor University, School of Electronic Engineering, \\ Dean Street, BANGOR LL57 1UT \\ Wales, UK
}

\begin{abstract}
Since the establishment of the Photonics Academy of Wales in 2005, several generations of participants have been encouraged to use their imagination in devising, designing and building novel photonics devices of benefit to society. In pursuing photonics projects within PAWB, the participants have gained a practical proficiency in photonics experimentation and photonics product design.

The Photonics Academy of Wales @ Bangor ( PAWB) assumed responsibility for the coordination of a series of events in Wales, UK as part of global activities celebrating 2015 as the International Year of Light.

PAWB has worked with several organisations and individuals to devise a programme of events which are focussed on conveying the significance of light and its technologies to a broad swathe of the population. These events take into account the bi-lingual nature of Wales with significant events being delivered in the Welsh language. Arrangement and delivery of the events has largely been undertaken on a voluntary basis albeit with some funding having been obtained from supportive bodies and organisations.
\end{abstract}

The presentation will report on the events which were organised and also will present examples of novel photonics devices developed by students working with PAWB.

Being aware of the importance of creating an on-going interest in the topics treated during the International Year of Light, some attention will also be given to legacy activities beyond 2015. A specific concern is the identification of effective mechanisms for engagement with photonics industry.

Keywords : photonics; education and training ; outreach;

\section{Introduction}

Since the establishment of the Photonics Academy of Wales in 2005, several generations of participants have been encouraged to use their imagination in devising, designing and building novel photonics devices of benefit to society. In pursuing photonics projects within PAWB, the participants have gained a practical proficiency in photonics experimentation and photonics product design.

The Photonics Academy of Wales @ Bangor ( PAWB) assumed responsibility for the coordination of a series of events in Wales, UK as part of global activities celebrating 2015 as the International Year of Light.

PAWB has worked with several organisations and individuals to devise a programme of events which are focussed on conveying the significance of light and its technologies to a broad swathe of the population. These events take into account the bi-lingual nature of Wales with significant events being delivered in the Welsh language. Arrangement and

Optics Education and Outreach IV, edited by G. Groot Gregory, Proc. of SPIE Vol. 9946, 994605

(C) 2016 SPIE · CCC code: 0277-786X/16/\$18 · doi: 10.1117/12.2235270 
delivery of the events has largely been undertaken on a voluntary basis albeit with some funding having been obtained from supportive bodies and organisations.

This contribution reports on the events which were organised and also will present examples of novel photonics devices developed by students working with PAWB.

Being aware of the importance of creating an on-going interest in the topics treated during the International Year of Light, some attention will also be given to legacy activities beyond 2015. A specific concern is the identification of effective mechanisms for engagement with photonics industry.

Following the declaration by the UN on 20 December 2013, based on a proposal made by the European Physical Society that 2015 should be the International Year of Light (IYOL), the Photonics Academy for Wales at Bangor (PAWB) undertook to organise a series of events in Wales in support of the IYOL. PAWB prepared a document outlining a plan for activities in Wales to celebrate the IYOL but simultaneously sought expressions of interest from those who would be ready to organise or participate in such events. The initially declared aimed was to provide a variety of public events which will demonstrate the importance of light in supporting and enhancing life. It was indicated that such events would occur on a pan-Wales bilingual basis and should engage people in a range of settings. A particular emphasis will be on giving the general public 'hands-on ' opportunities to appreciate the role which light plays in daily life.

\section{Supportive Organisations}

Having sought engagement from a variety of organisations it is gratifying to report a positive response from several quarters - some of which were unforeseen. Rather than attempt to arrange those responses in any kind of order of importance the simplest and most direct way for indicating how such a response emerged is to present those contributions roughly in chronological order.

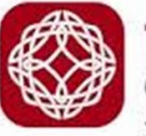

\section{THE LEARNED SOCIETY OF WALES} CYMDEITHAS DDYSGEDIG CYMRU CELEBRATING SCHOLARSHIP ANO SERVING THE NATION
DATHLUYSGOLHEICTOD A GWASANAETHURR GENEOL

The first organisation which responded in a practical way was the Learned Society of Wales. The Learned Society of Wales (LSW) (http://learnedsocietywales.ac.uk/) is an independent, all-Wales, self-governing, pan-discipline educational charity, providing public benefit including expert scholarly advice on a variety of public policy issues related to science, engineering, medicine, arts, humanities and social sciences. Established in 2010, the Society draws upon the considerable strengths of over 350 distinguished Fellows based in Wales, the UK and beyond. The Society, Wales's first national scholarly academy, aims to establish itself both as a recognised international representative of the world of Welsh learning, and as a source of authoritative, scholarly, and critical comment and advice on policy issues affecting Wales.

One of the present authors (KAS) is a member of the Council of the LSW and when he presented a short paper to the LSW Council the then Chief Executive of the LSW Dr Lynn Williams immediately made an offer of sponsoring a Christmas Lecture for Schools on the topic 'Chemistry and Light '. This was delivered in Bangor - and the seats could have been filled twice over. It is stressed that this was Christmas 2014 and so IYoL in Wales got off to an early start and, literally with a bang.

A major cultural event in Wales is the National Eisteddfod of Wales. This week-long annual peripatetic event draws in excess of 250,000 people of all ages to locations across Wales ( http://www.eisteddfod.org.uk/english/2015/). In 2015 the National Eisteddfod was held in Meifod, mid Wales. In 2015 the LSW has also offered its annual National Eisteddfod lecture as part of the IYOL activities. This lecture was delivered ( in Welsh ) by one of the present authors (KAS).

The second organisation which enthusiastically embraced the IYOL was the Welsh Optoelectronics Forum (http://www.wof.org.uk/home/). The Forum is a consortium of Welsh companies, University research groups, users and 
support organisations, formed following the impetus of activities in north Wales, and is dedicated to the development and profitability of the opto-electronics sector in Wales and internationally. Opto-electronics is all around and part of everyone's daily life, and probably those who will gain most from the Forum are the people and companies for whom the technology currently forms a small part of their work. Alongside the several anniversaries which underpin the choice of 2015 as the IYOL, it happens that 2015 marks 20 years of activity by the Welsh Optoelectronics Forum (WOF) .

2015 also is the $10^{\text {th }}$ anniversary of the establishment by WOF of the Photonics Academy for Wales. It is natural therefore that both these organisations will contribute to IYOL events.

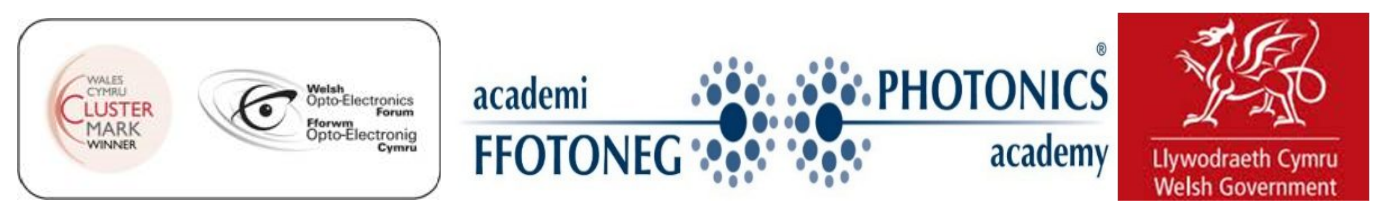

An approach was made to the Chief Scientific Adviser for Wales (CSAW) Professor Julie Williams for both moral and financial support for IYOL events and specifically for the formal launch of the IYOL in Wales which is described in more detail below. One records with great appreciation the support thereby forthcoming.

One may say that many of the foregoing organisations would have been fully expected to join IYOL activities. It is pleasing to record that support has come from rather unexpected directions.

The National Museum of Wales( http://www.museumwales.ac.uk/) - and in particular Dr Jana Horak - has embraced the IYOL with considerable imagination and energy. Dr Horak has organised a number of events under the title 'Geology and Light ' in the period June-August 2015.

The North Wales International Music Festival http://nwimf.com/home/index.html .- led by Anne Atkinson - has adopted light as the motif for its events in September/ October (In 2014 its theme was literature - related to the centenary of the birth of the poet Dylan Thomas.) It happens that there has historically been a strong link between the Welsh Optoelectronics Forum and the North Wales Music Festival. However WOF cannot claim any credit for the decision by Anne Atkinson to adopt light as a theme for the 2015 North Wales Music Festival. It appears that Anne Atkinson picked up early indications of the IYOL and decided to use it for the festival.

\section{Programme of Events}

PAWB has worked with several organisations and individuals to devise a programme of events which are focussed on conveying the significance of light and its technologies to a broad swathe of the population. The target was to have an event per month somewhere in Wales These events take into account the bi-lingual nature of Wales with significant events being delivered in the Welsh language. Arrangement and delivery of the events has largely been undertaken on a voluntary basis albeit with some funding having been obtained from supportive bodies and organisations. The following are events in which PAWB participated during the year. 


\subsection{PAWB Activities}

1. December 2014 Learned Society of Wales Schools Christmas Lecture 'Chemistry and Light'.

2.

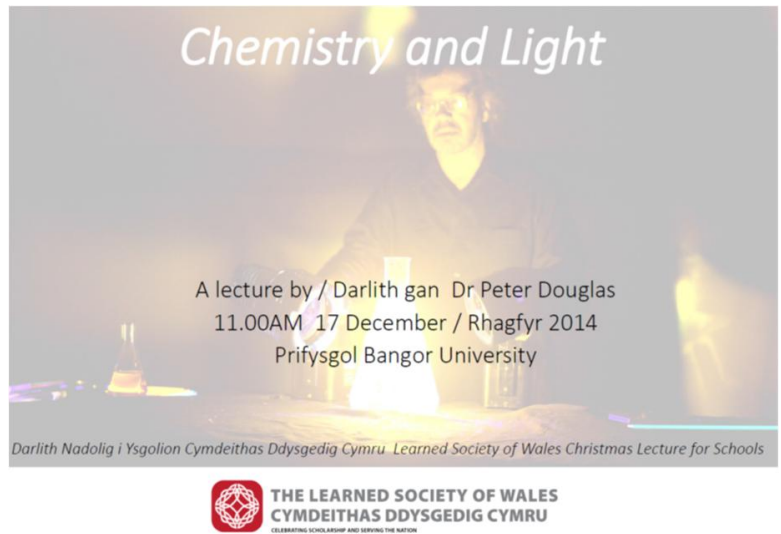

$20^{\text {th }} / 21^{\text {st }}$ January IYOL Launch UNESCO Paris

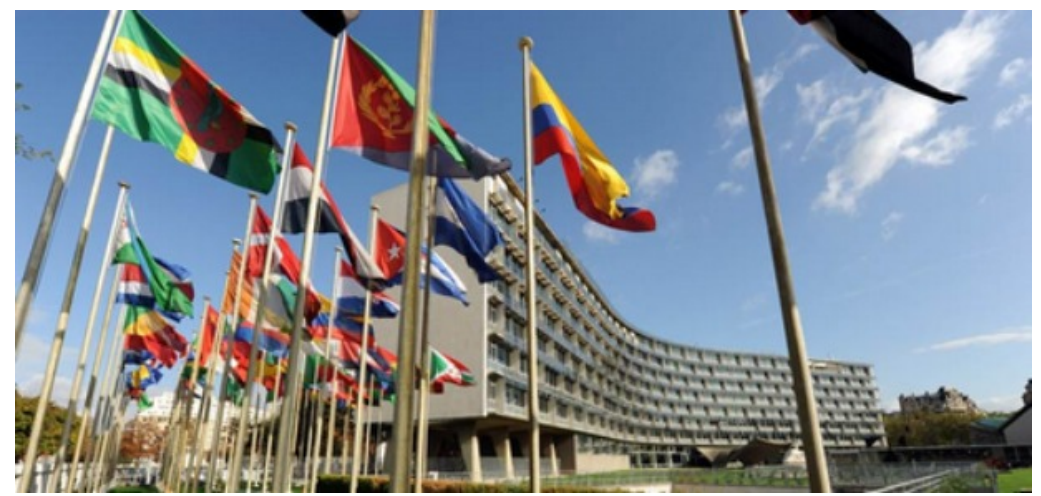

$5^{\text {th }}$ February IYOL Launch Wales, Cardiff ( see section 2.2 below)

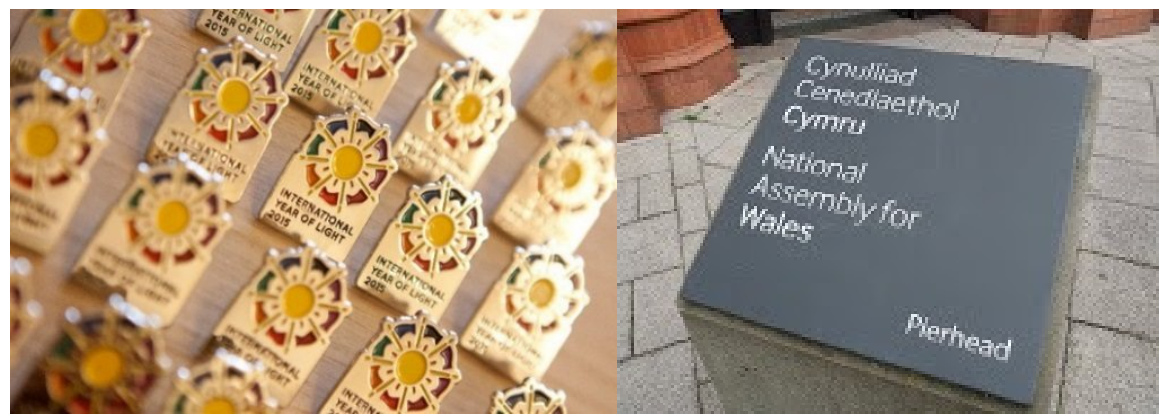

3. $31^{\text {st }}$ March-2 $^{\text {nd }}$ April SIOE Conference Cardiff

4. 16 $^{\text {th }}-18^{\text {th }}$ February PAWB Photonics Project Master Class led by Ray Davies-students from Friars School, Bangor 

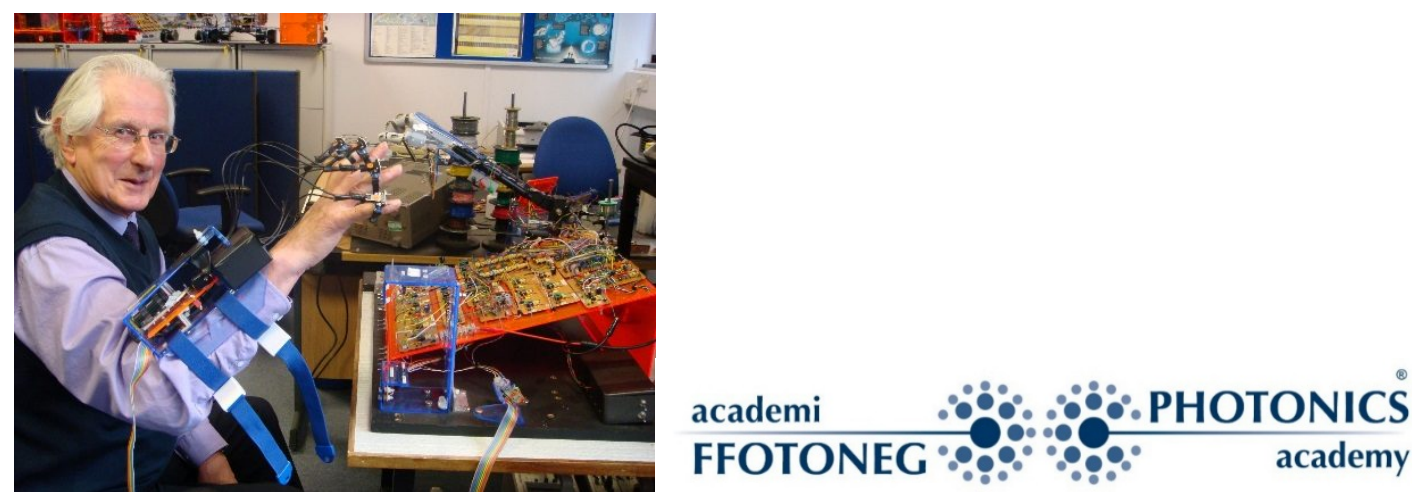

5. 4th March OpenIQE Photonics Innovation Camp-OpTIC : PAWB Display

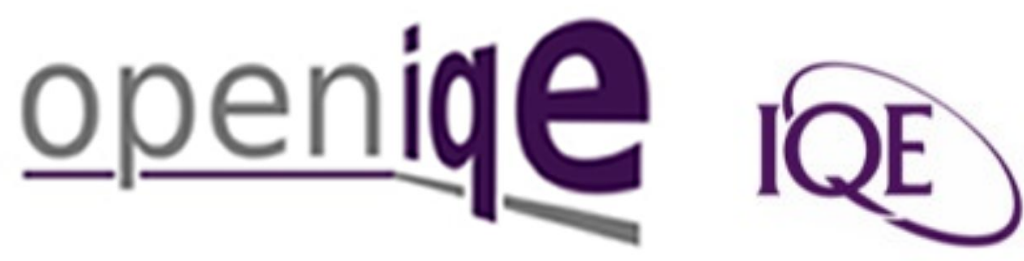

6. $14^{\text {th }}$ March Hidden Worlds Exhibition -Bangor Science Festival

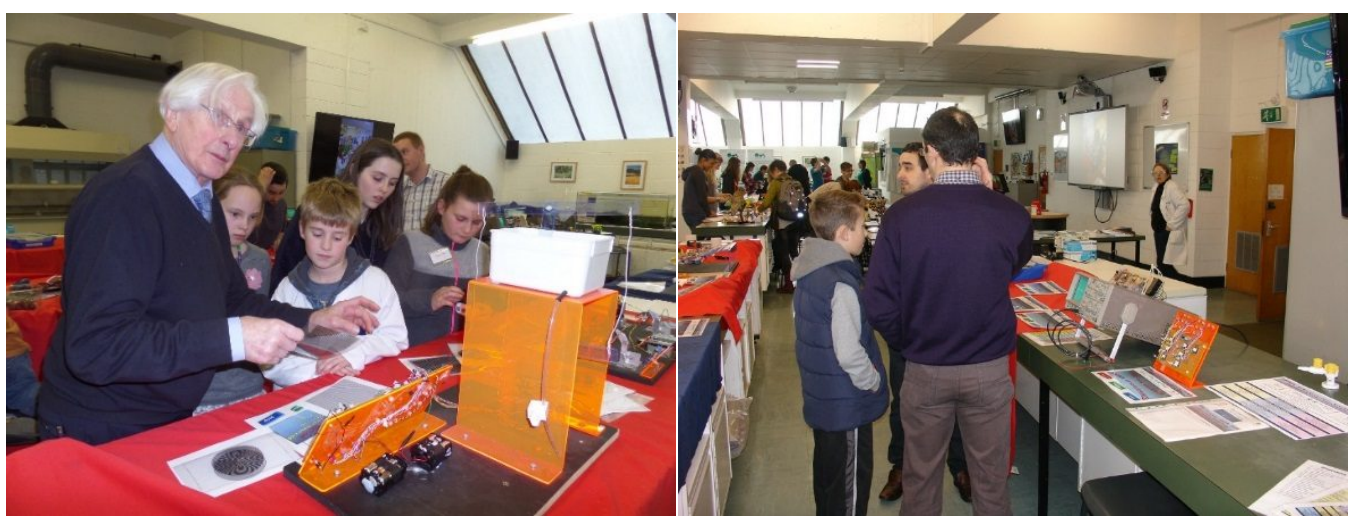

7. 25 $^{\text {th }}$ March EESW Project Presentation Day at Venue Cymru, Llandudno Projects : Roof Prism Optical Compass; Fibre Optic Laser Speckle Cardiopulmonary Resuscitation (CPR);Blind Person's Stair Ascending/Descending Sensor ; Ray Davies,PAWB 


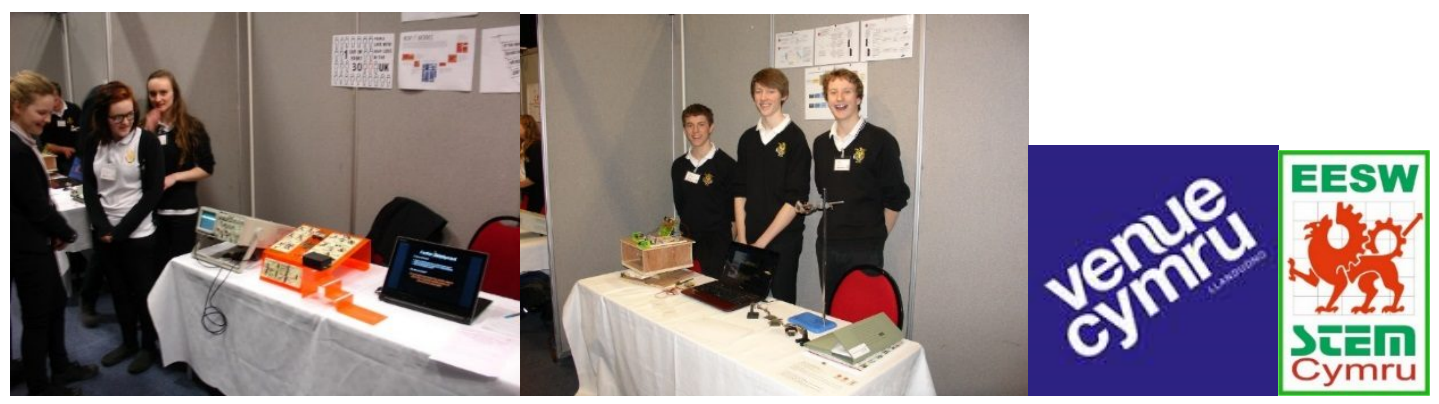

8. 21 ${ }^{\text {st }}$ April "Surprised by Light" - Phoenix Society - Kidderminster

9. $16^{\text {th }}$ June Bright Lights and Engineering, Knowledge Transfer Network, OpTIC Glyndwr, St Asaph
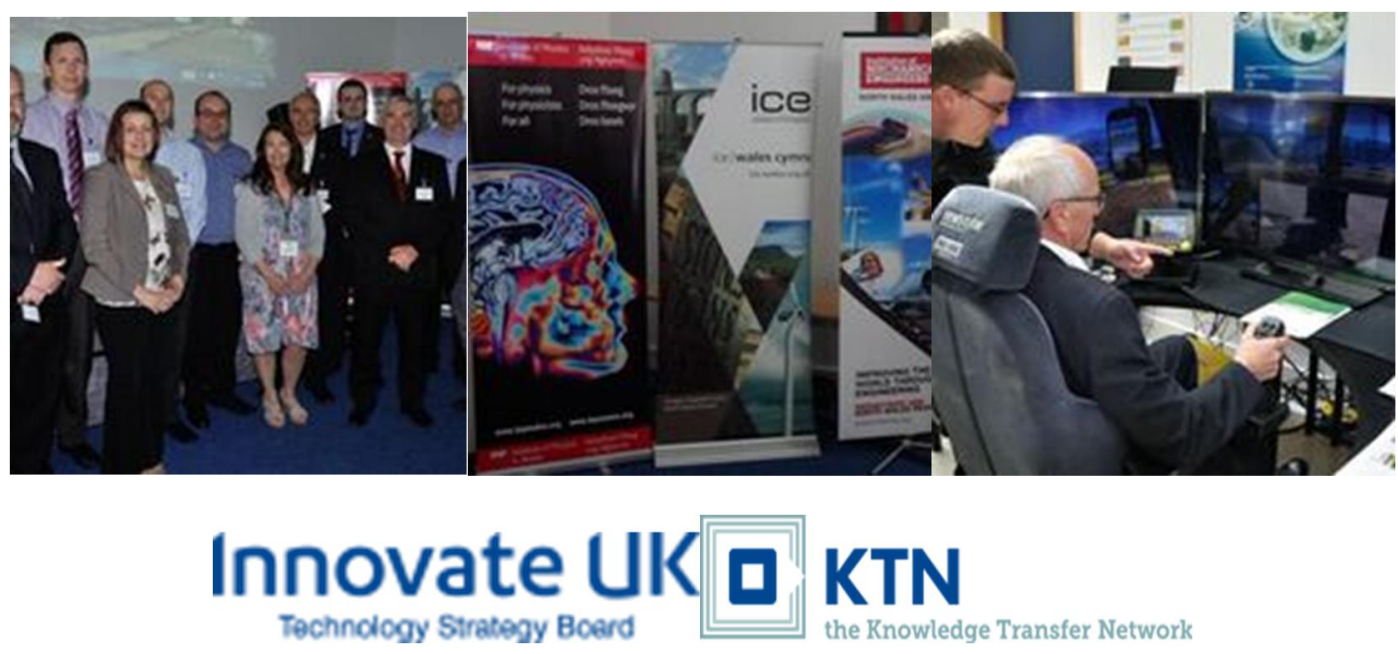

$10.20^{\text {th }} \mathrm{June} / \mathbf{2 5}^{\text {th }} \mathrm{July} / \mathbf{1 5}^{\text {th }}$ August Geology and Light : National Museum of Wales, Cardiff, Ray Davies, PAWB

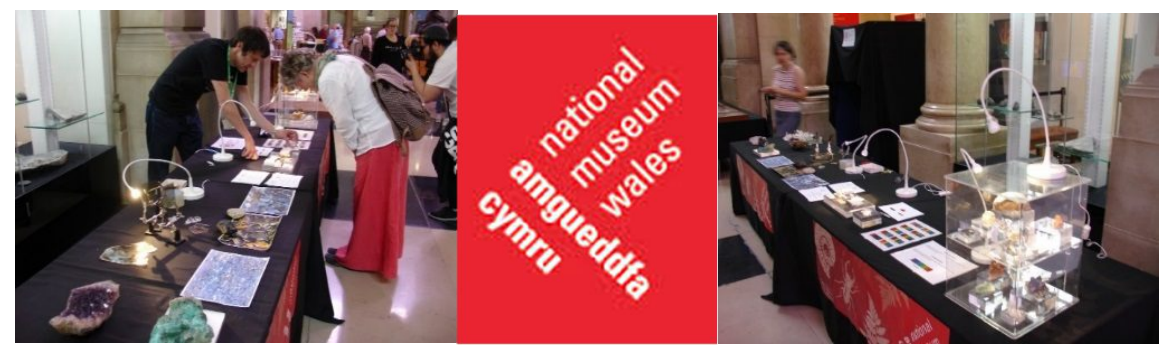

11. $2^{\text {th }}$ June $-2^{\text {nd }}$ July : Educational and Training in Optics and Photonics ( ETOP) 2015 Bordeaux, France : presentation by K Alan Shore

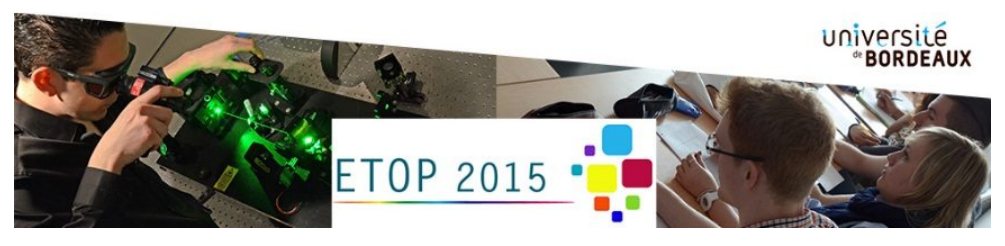


$12.5^{\text {th }}-10^{\text {th }}$ July Desborough College Photonics Course, Ray Davies,PAWB

13. July-August PAWB Master Classes for schools and colleges: Ray Davies

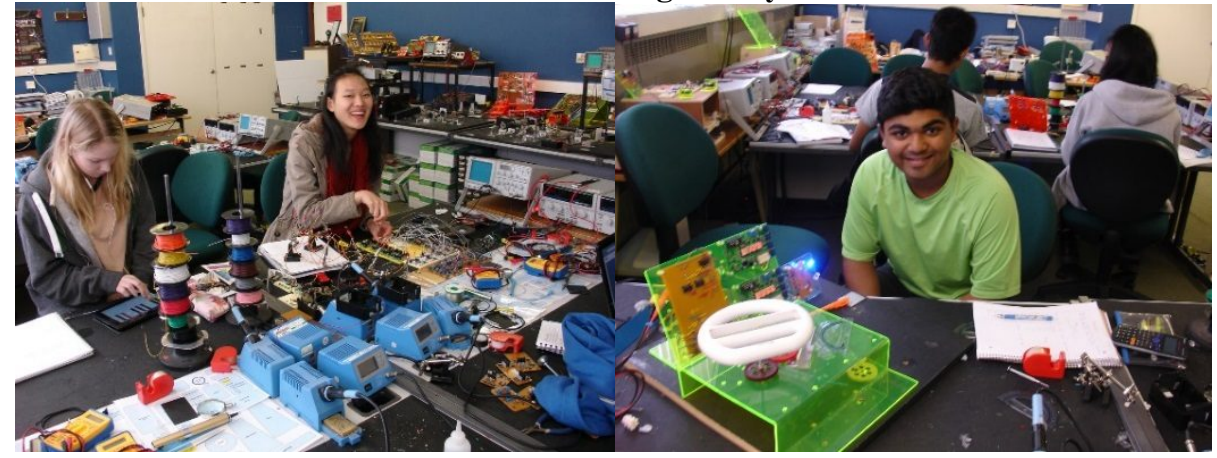

14. $1^{\text {st }}-8^{\text {th }}$ August National Eisteddfod of Wales (Meifod) : Learned Society of Wales Annual Eisteddfod Lecture : " Grym Golau ( The Power of Light) " lecture by K Alan Shore (right) ; chair Professor Ken Morgan ( left)

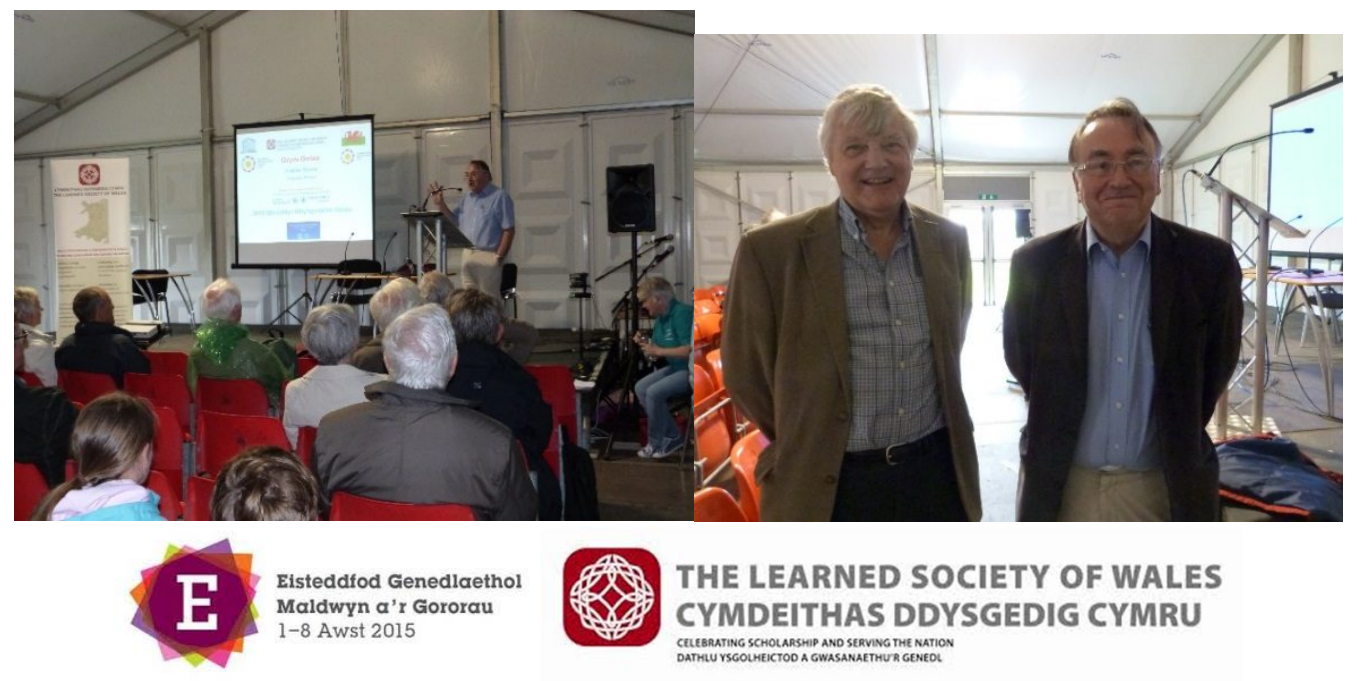

15. 2nd September, 'International Year of Light ' lecture by K Alan Shore, Taiyuan University of Technology, Shanxi, China

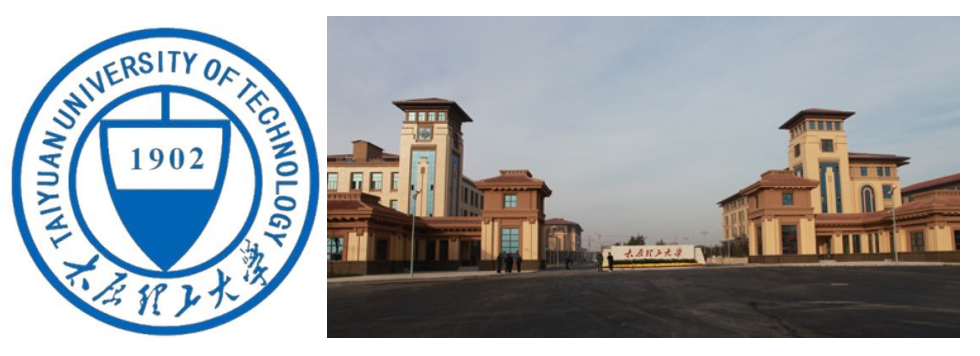




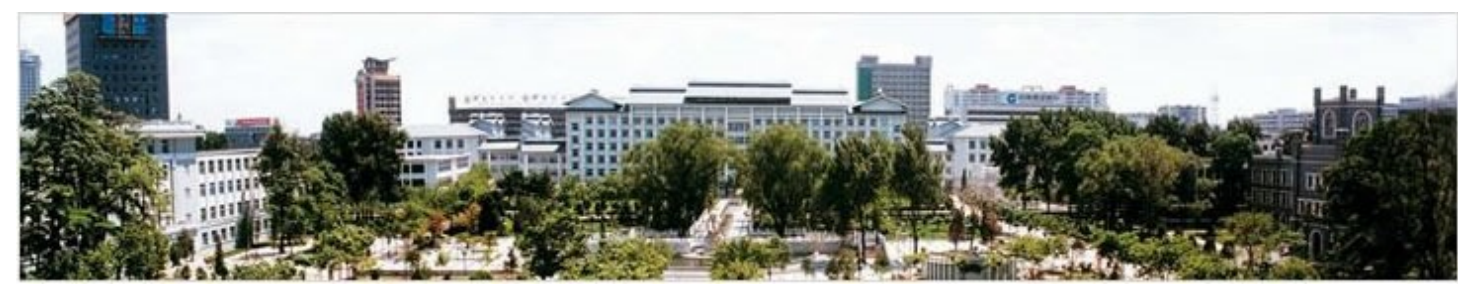

16. $17^{\text {th }}$ September : National Research Network in Advanced Engineering sponsored public lectures on photonics technologies : Dylan Thomas Centre Swansea “ The Year of Light “ lecture by K Alan Shore
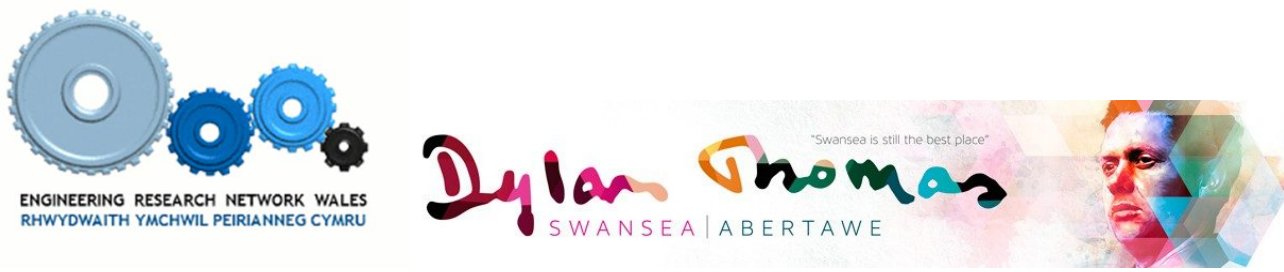

17. 25 ${ }^{\text {th }}$ September Lightfest @ Aston University,Birmingham

18. $1^{\text {st }}$ October North Wales Music Festival : PAWB Workshop for Schools including performance of optical music led by Ray Davies at St Asaph Cathedral ; featured also by Science Café, Radio Wales

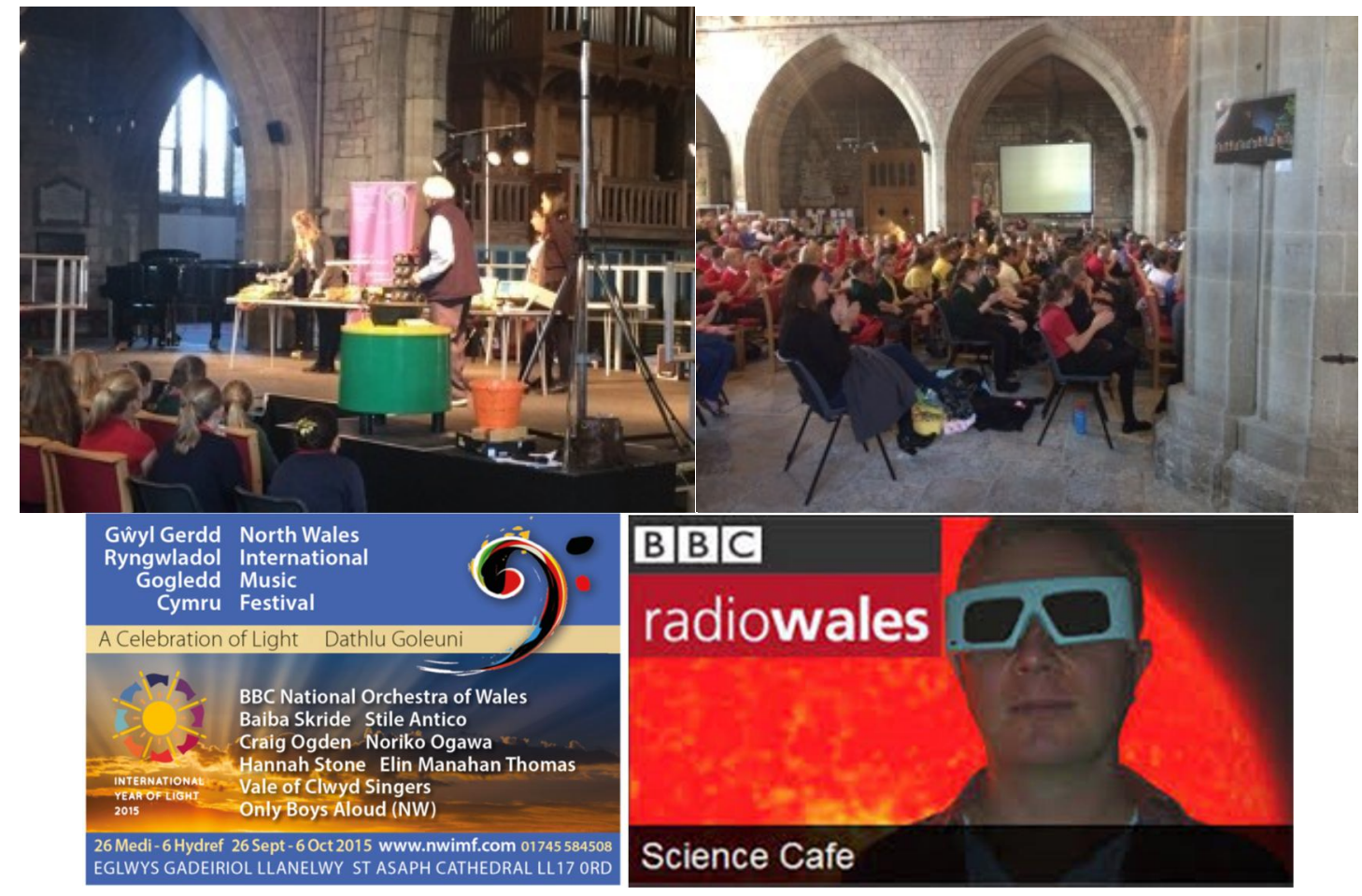

19. $20^{\text {th }}$ November : Lecture at Ysgol Bro Morgannwg, Barry by K Alan Shore 


\section{IIIII) YSGOLGYFUN BROMORGANNW}

20. 27 $7^{\text {th }}$ November 2015 Bangor University Annual Engineering Public Lecture : Sir Michael Berry, Bristol University "Quantum Mechanics and the Democratization of Music"

\section{PROFESSOR SIR MICHAEL VICTOR BERRY, FRS}

Melville Wills Professor of Physics (Emeritus), University of Bristol

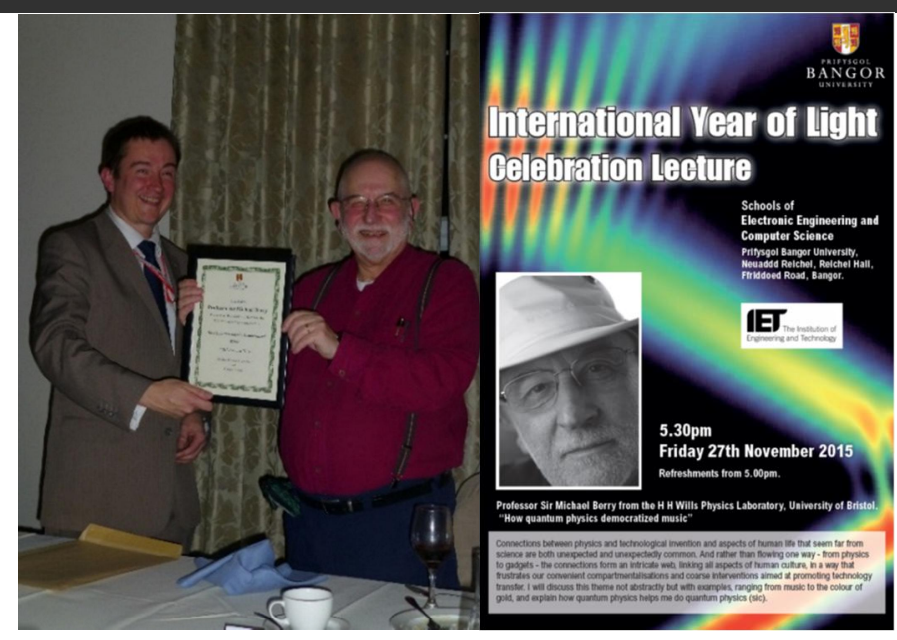

21. $2^{\text {nd }}$ December Official Opening of the Plas Heli sailing centre, Pwllheli, north Wales
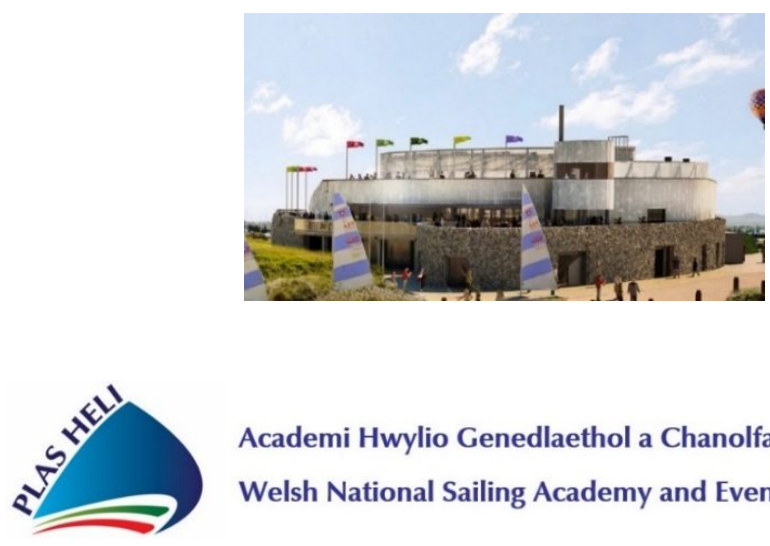

Academi Hwylio Genedlaethol a Chanolfan Ddigwyddiadau

Welsh National Sailing Academy and Events Centre

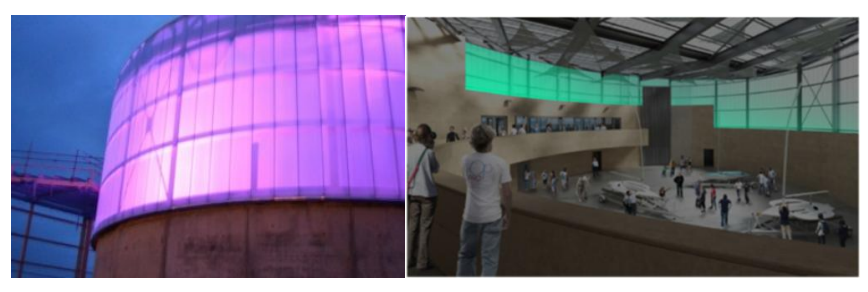


Wind is integral to sailing. The large Danpalon drum of the new Plas Heli

Sailing Centre provides an opportunity to transform the space into a light box

at night, displaying a visual representation of the wind through data

responsive lighting.

22. $14^{\text {th }} / 5^{\text {th }}$ December PAWB EESW Photonics Project Mentoring Sessions for Coleg Menai students led by Ray Davies

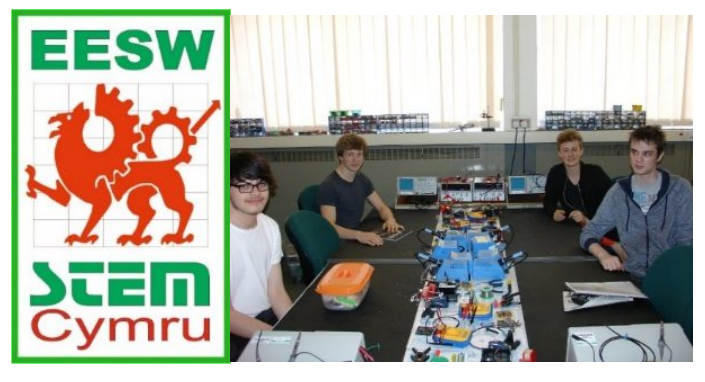

\subsection{IYOL Wales Launch}

It is wished to draw particular attention to the IYOL Wales Launch. The event took place on the $5^{\text {th }}$ February in the Pierhead Building, which is adjacent to the Welsh Senedd - the home of the Welsh Assembly in Cardiff Bay. The event was formally sponsored by Mrs Edwina Hart Welsh Government Minister for the Economy,Science and Transport. The Wales Launch of the International Year of Light was attended by representatives of a broad cross section of companies and organisations which have an interest in photonics. The launch event was addressed by Mrs Hart, Professor Julie Williams, Chief Scientific Adviser for Wales ; Karin Burger of SPIE Europe ; Dr Louise Jones of the Knowledge Transfer Network and Dr Beth Taylor of the Institute of Physics who chairs the UK organising committee for the IYOL. The event was chaired by Prof Alan Shore of PAWB. The event also included displays and exhibits by photonics companies and supporting organisations. The Learned Society of Wales, who exhibited at the event, also supported the costs of Simon Gough Photography who provided several of the following images.

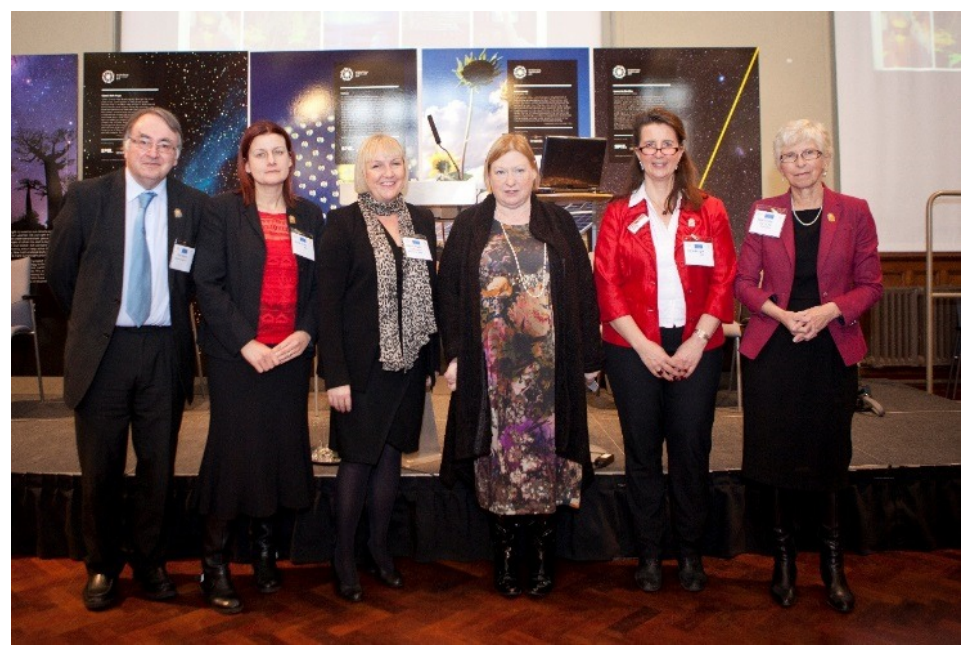

Speakers at the Wales Launch of the IYOL,Cardiff, February 2015 from left to right :

KAS ; Dr Louise Jones ; Professor Julie Williams,

Mrs Edwina Hart, Karin Berger and Dr Beth Taylor

Learned Society of Wales /Simon Gough Photography 
Karin Berger contributed very generously of her time in organising the event and notably for ensuring that all the logistics associated with the exhibits were efficiently undertaken. SPIE also provided the background displays used at the launch.Thanks are due to Dr Zubaida Sattar and Daniel Roberts for bringing some examples of Photonics Academy of wales@ Bangor (PAWB) activity to the IYOL Wales launch. Dr Sattar is a Ser Cymru Advanced Engineering NRN post doctoral researcher ; Dan is a PhD student supported by y Coleg Cymraeg Cenedlaethol. Unfortunately Ray Davies who is the motive force behind PAWB was indisposed at the time of the event.

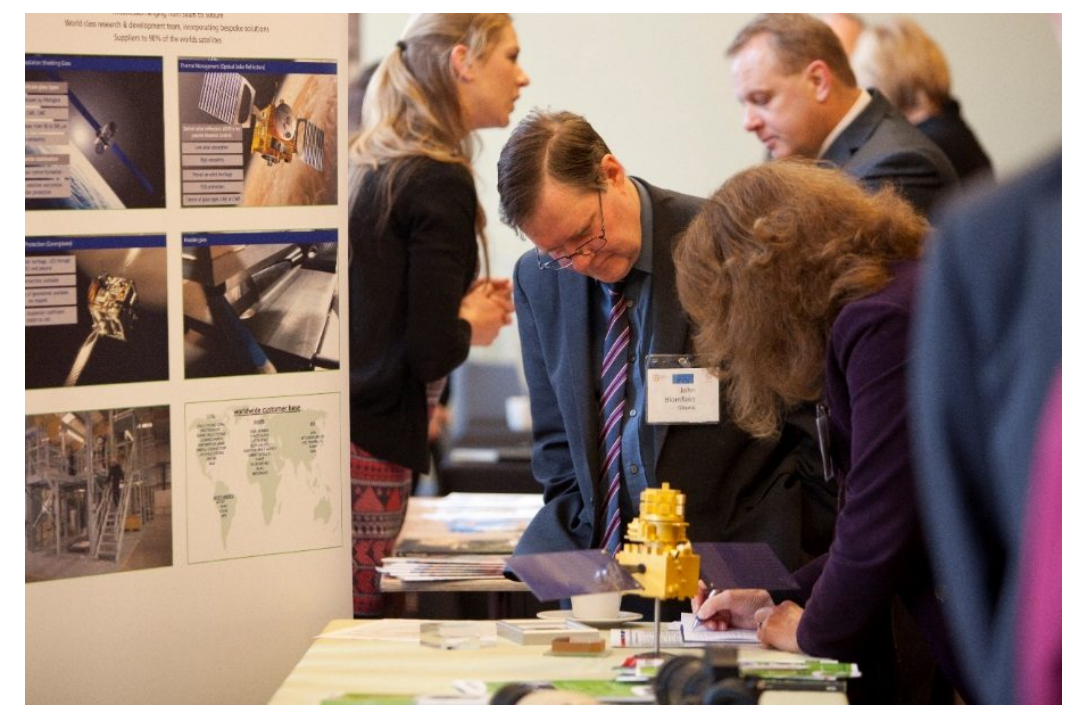

Attendees at a company display

Learned Society of Wales /Simon Gough Photography

\section{Legacy}

Being aware of the importance of creating an on-going interest in the topics treated during the International Year of Light, attention is being given to legacy activities beyond 2015. PAWB has the ambition to establish a Photonics Design Challenge as a means for engaging young people in hands-on photonics. The mechanism for implementing that challenge is under active consideration. In the meantime PAWB has continued its activities in diverse means.

An exemplar of such activity is a collaboration between PAWB and a dance company to produce a performance at Bangor University's Art and Innovation centre 'Pontio' . Pontio is the Welsh for 'to bridge ' and the name encapsulates the interaction between the university and the local community. Pontio also aims to build bridges between the arts and the sciences as exemplified by the dance collaboration engaged with by PAWB. As a further development of such artscience interaction it is hoped that a 'light artist ' will be involved with 'Pontio 'to create a 'light meadow' in the foreground to the building. In a separate such development a centre for sailing recently in Pwllheli, north Wales aims to include photonics exhibits as part of its on-going activities.

A long-established activity of PAWB is its Photonics Academy Summer School ( PASS) which typically attracts of order 20 high-school students in the $15-17$ age range. These students spend 4 to 8 weeks in the PAWB laboratory and during this time they are expected to devise, design and implement a novel photonics device of societal benefit. In 2016 about 16 students will participate in PASS during July and August. Some funding for this activity was gratefully received from the Sêr Cymru National Research Network in Advanced Engineering and Materials. In addition, several students attending PASS benefited from support from the Nuffield Foundation.

It is stressed that during PASS the participating students must themselves identify the challenge which they will face. This requirement exemplifies the PAWB approach. The essence of the PAWB approach is enunciated in Appendix which is a facsimile of a tutorial offered to PASS participants. 


\section{Conclusions}

The International Year of Light provided a platform for the widespread communication of the opportunities offered by light and its technologies. The Photonics Academy of Wales@ Bangor

( PAWB) energetically contributed to International Year of Light activities including in many non-traditional venues. PAWB has maintained the momentum of its activities to establish a legacy for the International Year of Light.

Acknowledgement : KAS gratefully acknowledges the financial support provided by the Sêr Cymru National Research Network in Advanced Engineering and Materials.

\section{Appendix 1 : The PAWB Approach to Photonics}

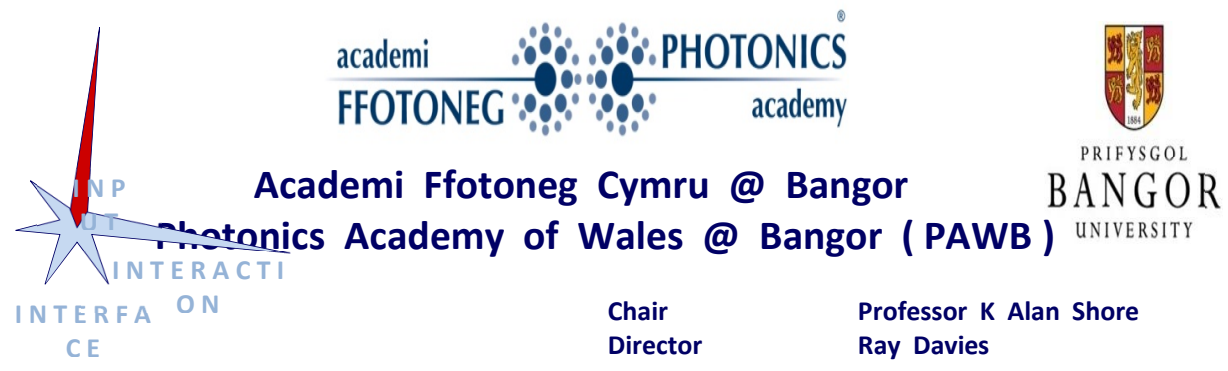

PAWB Laboratory 212,

School of Electronic Engineering, Bangor University, Dean Street, Bangor, Gwynedd, LL57 1UT

Website http://pawb.bangor.ac.uk/index.php.en

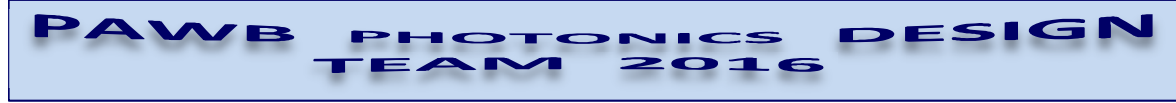

The PAWB Approach to Photonics

\section{Highlighting the PAWB TRIAD of INPUT INTERFACE INTERACTION - with SOLUTION Visions}

1 PAWB often claims that, over the last two decades, PAWB has developed a special PAWB Approach to Photonics. This Tutorial is an attempt to explain that special PAWB Approach to Photonics.

2 The fundamental postulate of the PAWB Approach to Photonics is a highly practical response to the crucially important philosophically relevant Question, when planning any Educational Learning Programme policy, namely:-

"When a new piece of Information is given to a student, what is that student meant to do with that piece of Information ?"

3 PAWB regards new Information as requiring a special Presentation Style, which should promote some kind of an immediate involvement response, from the student, to the specific new Information that has been presented. Each item of new Information should initiate some form of challenge to the student to become involved with, and to respond to, the new Information, through some personal INTERACTION with the reception of, and response to, the new Information.

4.1 Focusing just on the Laboratory Photonics Concepts, in all of the Laboratory based involvements and opportunities within the PAWB Approach to Photonics, the primary Photonics source of the Light Beam obviously is the essential INPUT signal, but it is the INTERFACE which is subsequently introduced to that primary INPUT signal which 
initiates some form of an optical INTERACTION - and it is within that optical INTERACTION that the real value of the Photonics enabling qualities reside.

4.2 Focusing just on the student receiving some Photonics Information, in the PAWB Approach to Photonics, any newly revealed Photonics Information is regarded as an INPUT signal - which is made available to the student, who constitutes the all-important student INTERFACE - and the hoped-for student's reception and response produces an INTERACTION, which may link the student to the new Photonics Information in highly valuable, and potentially innovative, ways.

5 In the specific PAWB Approach to Photonics, it is always the INTERFACE which is emphasized as being the really important, and useful, element - it is the optically receptive and responsive INTERFACE which yields the potentially creative and versatile nature of Photonics. Some form of Light INPUT is always necessary in any Photonics consideration or application, but the PAWB Approach to Photonics always emphasizes the relevant significance, and importance, of the receptive and responsive INTERFACE which is introduced to the Light INPUT to yield a specific, and useful, INTERACTION, which potentially can lead to the innovative new application of a Photonics Concept, which may be proposed by any PAWB student.

6 When first considering some Photonics Concepts, the importance of the Light INPUT is often emphasized, with the exclusion of the all-important receptively and responsively sensitive INTERFACE, which always needs to be introduced. It is the Laboratory introduced INTERFACE which encompasses the majority of the really useful parameters. It is the Laboratory introduced INTERFACE which can yield the appropriately envisaged potential new applications arising from the receptive and responsive INTERACTIONS produced by an INTERFACE interrupting an optical INPUT signal. The Light INPUT is essential within any Photonics situation, but it is the INTERFACE which yields the useful INTERACTIONS which are so valuable within the design of new and original Photonics applications. The PAWB Approach to Photonics always emphasizes the role of an INTERFACE.

7 The PAWB Approach to Photonics promotes an emphasis on the TRIAD of INPUT INTERFACE $~$ INTERACTION, and this TRIAD Approach is adopted within the subsequent Laboratory Empirical Investigations, as well as within the initial Presentation of Photonics Information to students, but always with a specific emphasis on the optical INTERFACE components.

8 The PAWB Approach to Photonics is interested in how any given INTERFACE can INTERACT with a Light INPUT Signal.

9 The PAWB Approach to Photonics is based on well-established Educational Philosophical principles. In the highly relevant Philosophical words about Education, expressed by the Greek Philosopher and Scientist, Socrates (469399 BC):-

"Education is the kindling of a flame - not the filling of a vessel".

The PAWB Approach to Photonics is not just about Photonics Concepts - it is about an INTERFACE with Light experiences.

\subsection{The TRIAD PAWB Approach to Photonics - INPUT Phase}

10.1.1 Students are introduced to LED, Laser Diode, and HeNe Laser Light Beams as the potential Light INPUT.

10.1.2 Rather than just making Photonics Observations, students are encouraged to "get rid of their eyes", and they are introduced to making quantifiable measurements of Light Intensity INPUT Signals, utilizing Photodiodes connected to PAWB specifically designed Op-Amp Circuits, with d.c. and a.c. input and output capabilities. 10.1.3 Light Beam Safety standards are always clearly established.

\subsection{The TRIAD PAWB Approach to Photonics - INTERFACE Phase}

10.2.1 Students are provided with opportunities to introduce Photonics INTERFACES to the Light Beam INPUTS. 


\title{
10.2.2 INTERFACES include:
}

\author{
Front Silvered Mirrors \\ Coloured Filters \\ Prisms \\ Retro-reflectors
}

10.2.3 Laboratory INTERFACE Techniques of:

Circuits

\subsection{The TRIAD PAWB Approach to Photonics - INTERACTION Phase}

10.3.1 Student opportunities to witness INTERACTIONS:

Scattering

\subsubsection{The INTERACTION “Challenge":}

\author{
Spherical Lenses \\ Diffraction Gratings \\ Amici Prism \\ Fibre Optic Links
}

Cylindrical Lenses

Linear Polarizing Filters

Circular Polarizing Filters

Lens Combinations

$\begin{array}{lll}\text { Alignment } & \text { Tweak-ability } & \text { Steering Lenses } \\ \text { Mounting } & \text { Testing } & \text { Fault Finding } \\ \text { Soldering } & \text { Proto-boards } & \text { Power Supplies } \\ \text { Wiring } & \text { Fabrication } & \text { Integrated }\end{array}$

perceived?

$\begin{array}{llll}\text { Scattering } & \text { Reflection } & \text { Refraction } & \text { Diffraction } \\ \text { Interference } & \text { Coherence } & \text { Polarization } & \text { Laser Speckle } \\ \text { Photons } & \text { Wavelength } & \text { Electron Volt } & \text { Intensity Units } \\ \text { Oscilloscopes } & \text { Power Packs } & \text { Batteries } & \text { Photovoltaics } \\ \text { Fibre Optics } & \text { Fresnel Lens } & \text { Dispersion } & \text { Surface }\end{array}$

10.3.3 The INTERACTION Achievements: Operational Prototype Report Writing

Original Idea

What OBSERVATIONS actually are being undertaken ?

What might be possible as a Laboratory INVESTIGATION ?

perceived?

Share

\author{
Sense of Achievement \\ Presentation \\ Development Potential \\ Confidence \\ Poster \\ Community
}

11 As soon as a student has made an OBSERVATION of any one of the 30 Photonics Observable Concepts which the PAWB Approach to Photonics Kit provides, each individual student is "challenged" to activate, in highly practical ways, their own personal Imagination, Insight, and Ingenuity. Students are provided with the opportunities to make OBSERVATIONS from placing specifically selected INTERFACES in various Light INPUT Beams, and to carry out INVESTIGATIONS into the receptive and responsive INTERACTIONS, which each INTERFACE yields, and which ultimately may lead to the DESIGN of a new Invention.

12 Once a specific OBSERVATION has been made, the student's own participatory involvement extends to the consequential INVESTIGATION phase, whereby a series of MEASUREMENTS, and their INTERPRETATION, provide the Laboratory acquired EMPIRICAL EVIDENCE to support the DESIGN and TESTING of a fully operational Prototype Project, which will demonstrate the feasibility and effectiveness of the student's own ingenuity in proposing such an imaginative DESIGN idea.

13 The PAWB Approach to Photonics seeks to "challenge" each student with an opportunity to devise a new application of any recently observed Photonics Concept - with PAWB guidance being provided in supporting that "challenge", at the very instant of each student first making the initial Photonics OBSERVATION of Light INTERACTING with an INTERFACE.

14 The PAWB Approach to Photonics emphasizes that any Photonics OBSERVATION of a Light-based INPUT signal, incident on a Photonics INTERFACE, will yield a receptive and responsive optical INTERACTION, with the potential to initiate the foundation SOLUTION to $\mathbf{1 0 0}$ New Inventions for the world of Photonics. PAWB students prove this reality very regularly.

15 "Education is the kindling of a flame", and this kind of approach to education is the PAWB Approach to Photonics. 